Minimah, M. D.

Prediction of Condensate Banking with Relative Permeability To Oil - Gas And Saturation In A Gas Condensate Reservoir.

\author{
Ddieboamadi005@gmail.com \\ Rivers State University, \\ Nkporlu - Oroworukwu \\ Port Harcourt, Rivers State, Nigeria \\ This article is covered and protected by copyright law and all rights reserved exclusively by the \\ Centre for Petroleum, Pollution Control and Corrosion Studies. \\ (CEFPACS) Consulting Limited. \\ Electronic copies available to authorised users.
}

The link to this publication is https://ajoeer.org.ng/otn/ajoeer/qtr-2/2020/02.pdf 


\title{
PREDICTION OF CONDENSATE BANKING WITH RELATIVE PERMEABILITY TO OIL - GAS AND SATURATION IN A GAS CONDENSATE RESERVOIR
}

\author{
Minimah, M. $\mathrm{D}^{\mathbf{1}}$, Ifeanyi, S. $\mathrm{N}^{\mathbf{2}}$, and Bright B. $\mathrm{K}^{\mathbf{3}}$

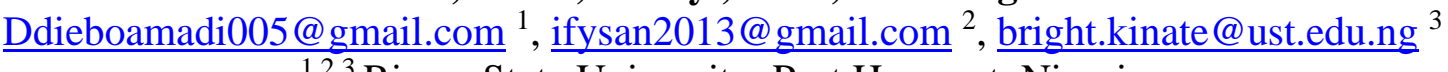 \\ ${ }^{1,2,3}$ Rivers State University, Port Harcourt, Nigeria
}

\begin{abstract}
:
Gas condensate fields are quite lucrative fields because of the highly economic value of condensates. However, the development of these fields is often difficult due to retrograde condensation resulting to condensate banking in the immediate vicinity of the wellbore. In many cases, adequate characterization and prediction of condensate banks are often difficult leading to poor technical decisions in the management of such fields. This study will present a simulation performed with Eclipse300 compositional simulator on a gas condensate reservoir with three case study wells- a gas injector (INJ1) and two producers (PROD1 and PROD2) to predict condensate banking. Rock and fluid properties at laboratory condition were simulated to reservoir conditions and a comparative method of analysis was used to efficiently diagnose the presence of condensate banks in the affected grid-blocks. Relative Permeability to Condensate and gas and saturation curves shows condensate banks region. The result shows that PROD2 was greatly affected by condensate banking while PROD1 remained unaffected during the investigation. Other factors were analyzed and the results reveal that the nature and composition of condensates can significantly affect condensate banking in the immediate vicinity of the wellbore. Also, it was observed that efficient production from condensate reservoir requires the pressure to be kept above dew point pressure so as to minimize the effect and the tendency of retrograde condensation.
\end{abstract}

\section{Keywords: Condensate Banking, Phase Production, Relative Permeability, Relative Saturation, Retrograde Condensation}

\section{INTRODUCTION}

Above dew point, gas condensate reservoirs are generally a single-phase homogenous mixture. As reservoir is depleted, the condition of temperature and pressure various. This often result to retrograde condensation in the reservoir system with the formation of two-phase fluid multicomponent system. Since experience from reservoir pressure transient behavior shows that largest pressure decline occurs in the immediate vicinity of the wellbore, it then follows that these will experience highest tendency of retrograde condensation and consequently, largest liquid dropout. This is as a result of pressure drop in the reservoir and in which case, most likely go below dew point with remarkable liquid saturation build up and corresponding heavy-ends dropout from the condensate system. (Hinchman and Barree,1985; Imo-jack, 2010; Lal,2003) From conservative literature, a lean gas condensate below the dew point produces less than the $100 \mathrm{STB} / \mathrm{MMSCF}$ of liquid, while on the other hand the rich fluid generates typically more than 150 STB/MMSCF (Fan et al,2005).

Condensates mobility (ratio of relative permeability to viscosity) has been shown by notable studies to be both space and time dependent. The implication of this is that at zones far from the well bore vicinity, the liquid is seemingly immobile due to low saturation and capillary forces while near the well bore vicinity, liquid saturation could be higher than critical value resulting to increase in 
mobility. For this reason, there is highly competitive flow of both phases through the wellbore thereby making the relative permeability of each phase a determinant factor during co-production of the fluids (Du et al.,2004; Gringarten et al.,2000).

Retrograde condensation is inevitably associated with the depletion of potential gas condensate reservoir. This process of retrograde condensation would normally continue with decreasing pressure until the liquid dropout reaches its peak value known as "critical condensate saturation". With further reduction in pressure, normal vapourization process of the heavy end molecules will commence. During this process, more condensate molecules transits to gas phase than liquid phase because fewer gas molecules are left to strike the liquid surface (Ahmed et al.,1998). This process is generally known as retrograde condensation. This behavior can be displayed in the phase diagram below.

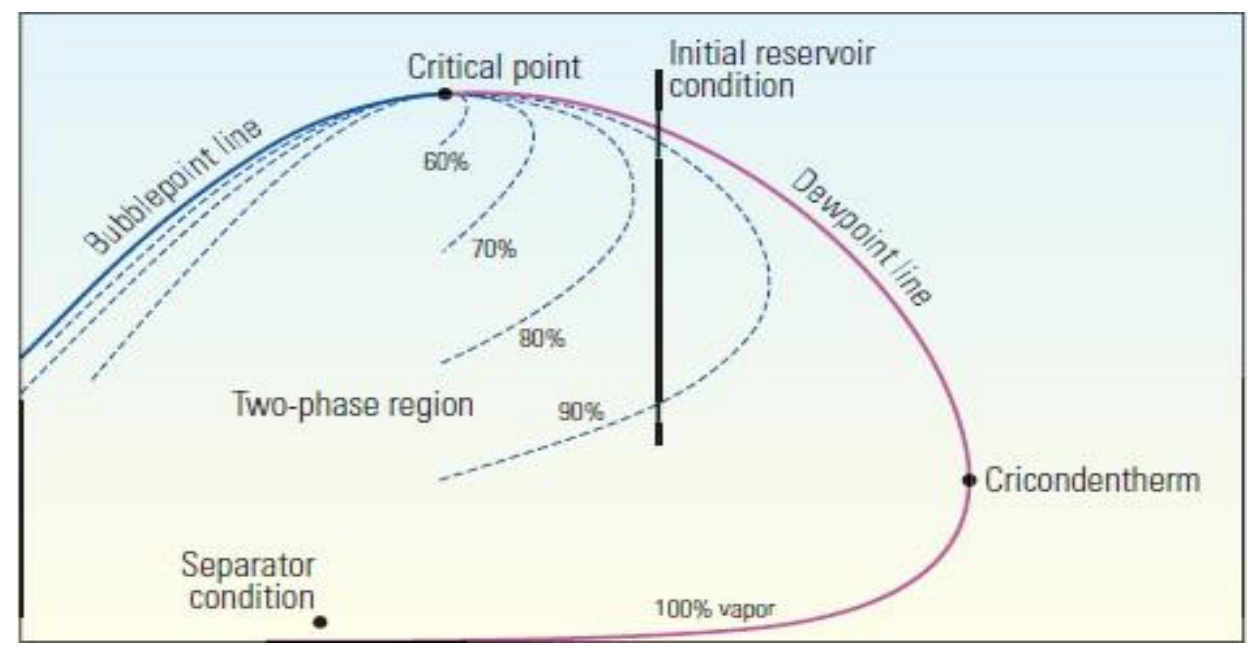

Figure 1.0: Phase Diagram of Gas-Condensate System (Fan et al.,2006)

The complex flow behaviors and thermodynamic characteristics associated with gas condensates makes them to be generally regarded as most complex reservoir system to manage. (Chunmei,2009). They are characterised by producing both gas and condensate liquid at surface conditions with a typical condensate reservoir producing about 3-150 MCF/STB gas/liquid ratios (McCain,1990)

The reduction in gas mobility due to liquid accumulation has been attributed by key studies as the effect of condensate banking (also known as condensate blockage). Several gas condensate fields worldwide producing below dew point has been reported to be associated with condensate blockage problems. A good example is the Arun field, which was operated by Mobil, now ExxonMobil, in which the loss in some wells was greater than 50\% (Afidick et al.,1994; Barnum et al.,1995; Silpngarmlers et al.,2005). Shell and Petroleum Development Oman also reported a 67\% productivity loss for wells in two fields.

Figure (2) depicts a schematic of productivity reduction due to condensate banking (Smits et al.2001). The effects of condensate accumulation within the immediate vicinity of the wellbore are often translated to the entire production life of the well. According to Abaku et al. (2020), the increased production of the condensates in its liquid phase causes a multi-phase flow in the wellbore which eventually leads to liquid loading in the wellbore. 


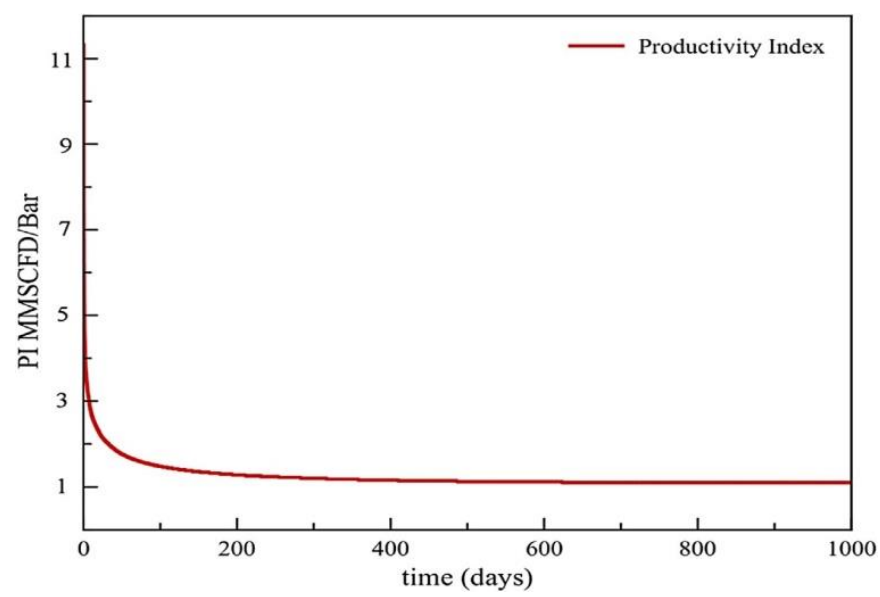

Figure 2: Schematic of PI Reduction (Smits et al.,2001)

\section{MATERIALS AND METHODS}

This study considers a composite 2D reservoir grid system with grid cell dimensions, 20x $1 \times 5$ (100 grid cells). The case study reservoir was produced for 10 years using two producers, PROD1loacted at $(10,1)$ and PROD2 located at $(20,1)$ and a gas injector at $(1,1)$. Prediction of future performance was made using a time step of 10 days over a 10 years production forecast. Based on the scope of this work, analysis were made using the reservoir grids associated with the wells $[(10,1)$ and $(20,1)]$ so as to fully characterize and predict condensate banking on the production life of the well. The rock and fluid properties were simulated at reservoir conditions. In developing the model, the following objectives were outlined:

- To build a fully composite 2D reservoir model using a rectangular block-centered gridding system

- To develop relative permeability/saturation plots of the suspected grid cells from simulation runs result and use results to identify regions/periods of condensate banking

- To predict other factors/effects of condensate banking on field performance using the simulated production history

The composite 2D Model was generated using ECLIPSE 300 compositional simulator with a case study of gas condensate reservoir. To ensure consistency with research aim, production and petrophysical parameters of the gridblocks in the immediate vicinity of the producing wells were specified in the summary section. The well completion schedule is presented in Table 2.0 below while the general simulation workflow employs a conventional ECLIPSE 300 simulation technique. In the analysis of simulation results obtained using the above algorithm, a comparative technique was employed between the case study producer wells located at $(10,1)$ and $(20,1)$ respectively. The performance of the two wells were analyzed together with other sensitive parameters that ultimately alters or determines the distribution of condensate banking in a gas condensate reservoir. For further insights, the distribution in the gasesous and liquid phase were analyzed

Table 1: Well Completion Schedule 


\begin{tabular}{llll}
\hline Location/Control Parameter & INJ1 & PROD1 & PROD2 \\
\hline Well Grouping & INJ & PROD & \\
i-location & 1 & 1 & 1 \\
j-location & 1 & 10 & 20 \\
k-upper & 1 & 1 & 1 \\
k-lower & 5 & 3 & 3 \\
Preferred Phase & Gas & Oil & Oil \\
Well type & Injector & Producer & Producer \\
Well Control Mode & GRAT/BHP & BHP & BHP \\
Wellbore raduis & & \multicolumn{2}{c}{$0.33 \mathrm{ft}$} \\
\hline
\end{tabular}

Table 2: Reservoir Fluid Specification

\begin{tabular}{lll}
\hline $\mathbf{S} / \mathbf{N}$ & Parameter & Description \\
\hline $\mathbf{1}$ & Reservoir Type & Gas Condensate \\
$\mathbf{2}$ & Number of Components & 6 \\
$\mathbf{3}$ & Component Names & $\mathrm{CO} 2$ \\
& & $\mathrm{~N} 2$ \\
& & $\mathrm{C} 1$ \\
& & $\mathrm{C} 3$ \\
& & $\mathrm{C} 10$ \\
$\mathbf{4}$ & & $\mathrm{C} 15$ \\
& & Peng Robinson \\
\hline
\end{tabular}

\section{RESULTS AND DISCUSSION}

The diagram in Figure (3) shows the composite reservoir model in rectangular coordinates as used in this study. The grids cells represent an uneven distribution of rock properties caused by reservoir heterogeneity. From the grid data used in this study, the reservoir system appears to have a remarkable dip angle. Predictions and characterizations of the system are based on the parameters discussed below. 


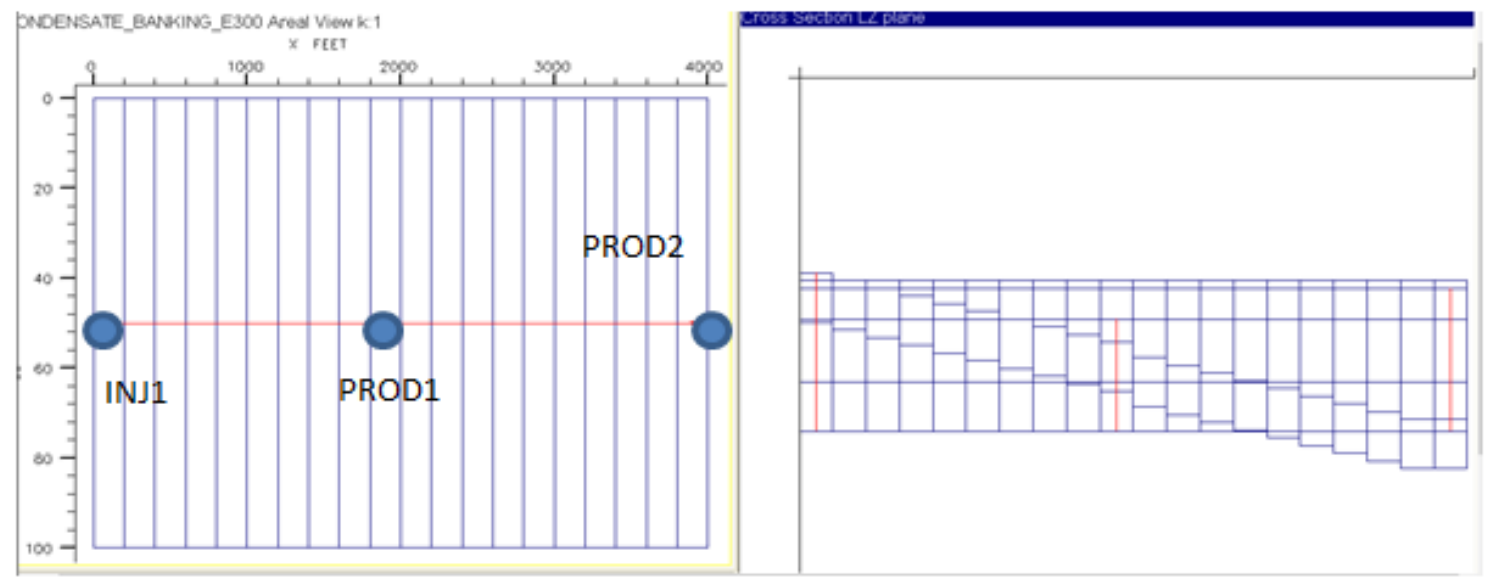

Figure 3: Cross-sectional view of the Reservoir Grid Layout Showing the Wells

\subsection{Effect of Condensate Banking on the Relative Permeability and Gas Saturation}

The results in Figure (4) below show the effect of condensate banking on the relative permeability of phase to liquid phase. The PROD2 bearing grid block was remarkably affected by condensate accumulation during the early life of the well until the effect of the gas injection was felt. At this time, the pressure transient effect of INJ1 provides additional drive energy needed to flow the condensate banks in the immediate vicinity of PROD2.

Correspondingly, the gas saturation and the oil (condensate) saturation history in Figure (5) shows that after about 28days of production, the gas saturation of PROD2 drops remarkably as the oil saturation (Condensate) increases to a peak value of $21.5 \%$. After 600days of production life of PROD2, the condensate bank disappears and normal single-phase gas production continues.

As has been clearly illustrated in the results of Figures 4 and 5, the effect of the condensate banking on the relative permeability to the two-phase systems causes mobility issues on the gas phase of the accumulated condensates in PROD2. 


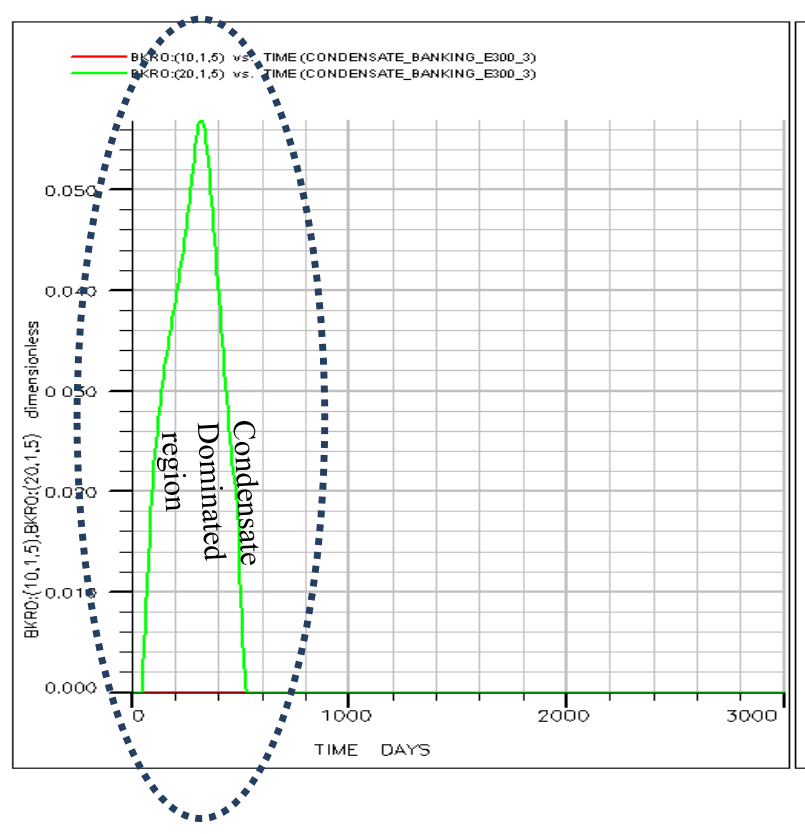

(a)Rel. Perm. to Oil (Condensate)

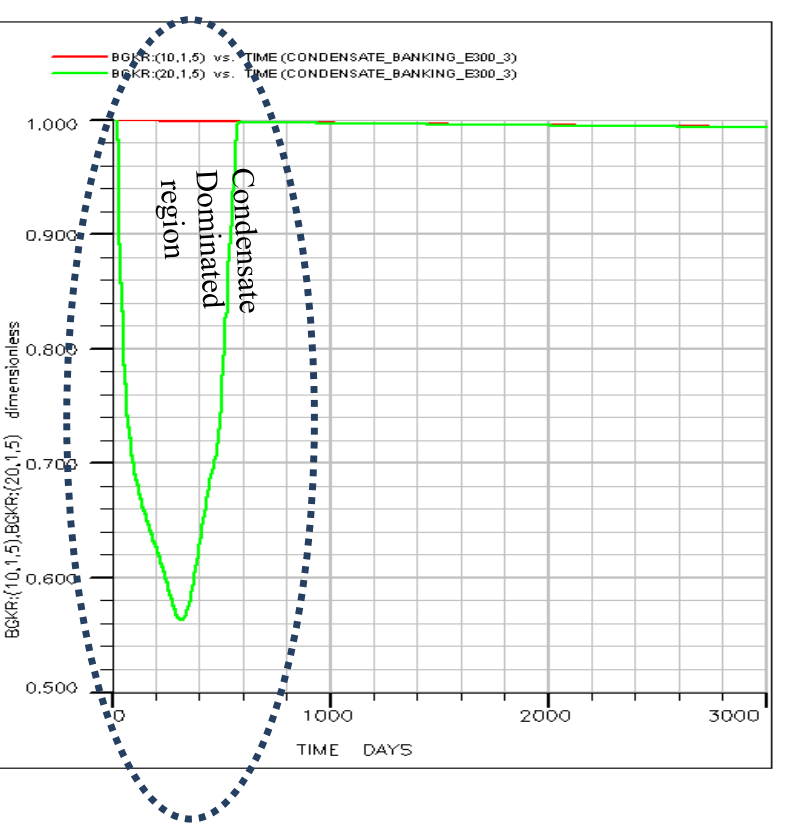

(b)Rel. Perm. To Gas

Figure 4: Effect Condensate Banking on Relative Permeability

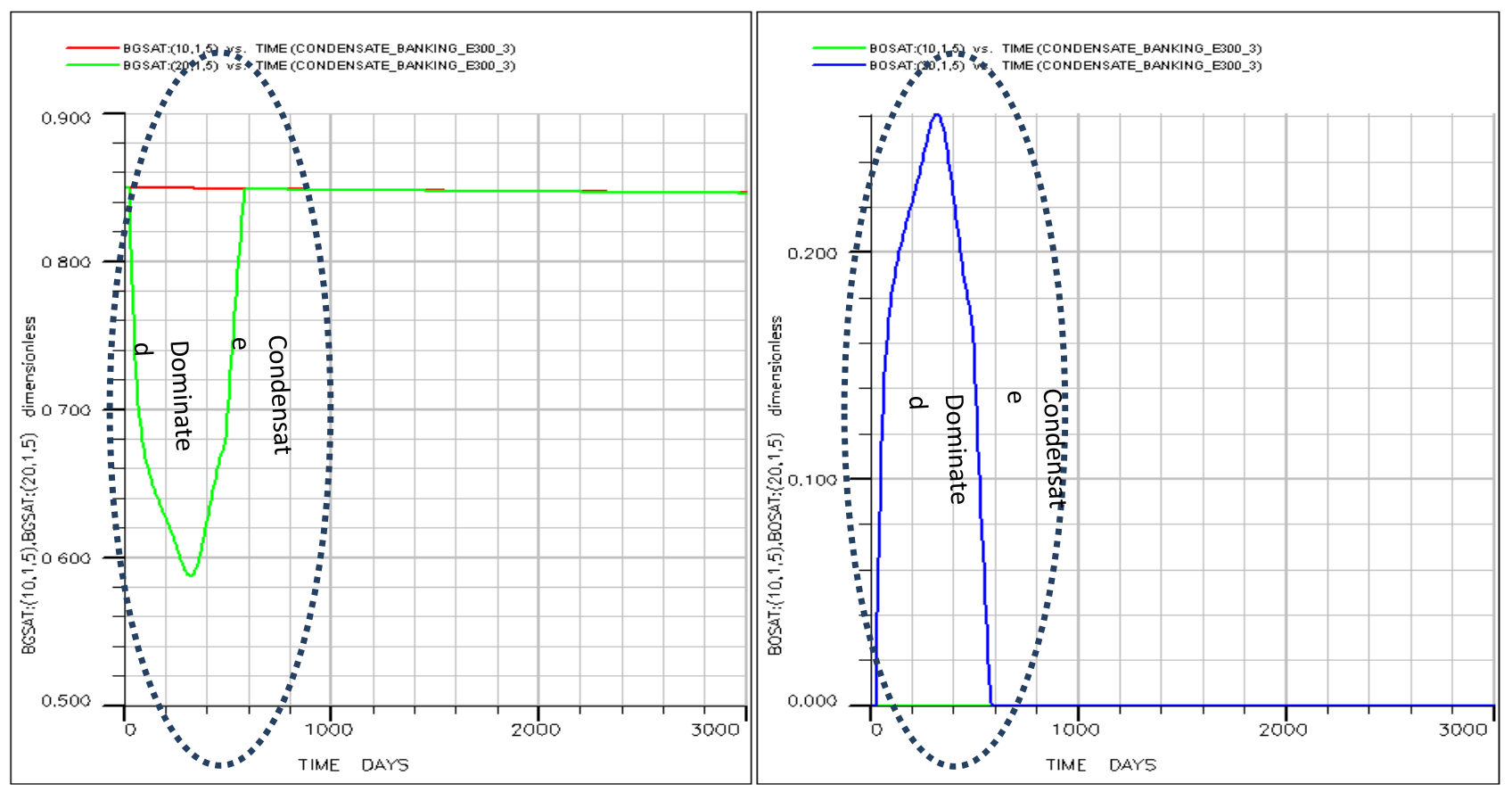

(a) Rel. Permeability to Gas

(b) Rel. Permeability to Oil (Condensate)

Figure 5: Effect of Condensate Banking on Gas and Condensate Saturation 


\subsection{Analysis of Well's Productivity Index}

The formation of condensates via retrograde condensation in the reservoir causes remarkable decline in the well's productivity. The result of Figure (6) presents the productivity index of the two producers. The areal sweep effect of INJ1 caused a remarkable decline in PROD1 PI as compared to PROD2. In the absence of the injector, it is expected that a remarkable decline in PI be observed in PROD2 as a consequence the accumulated condensates.

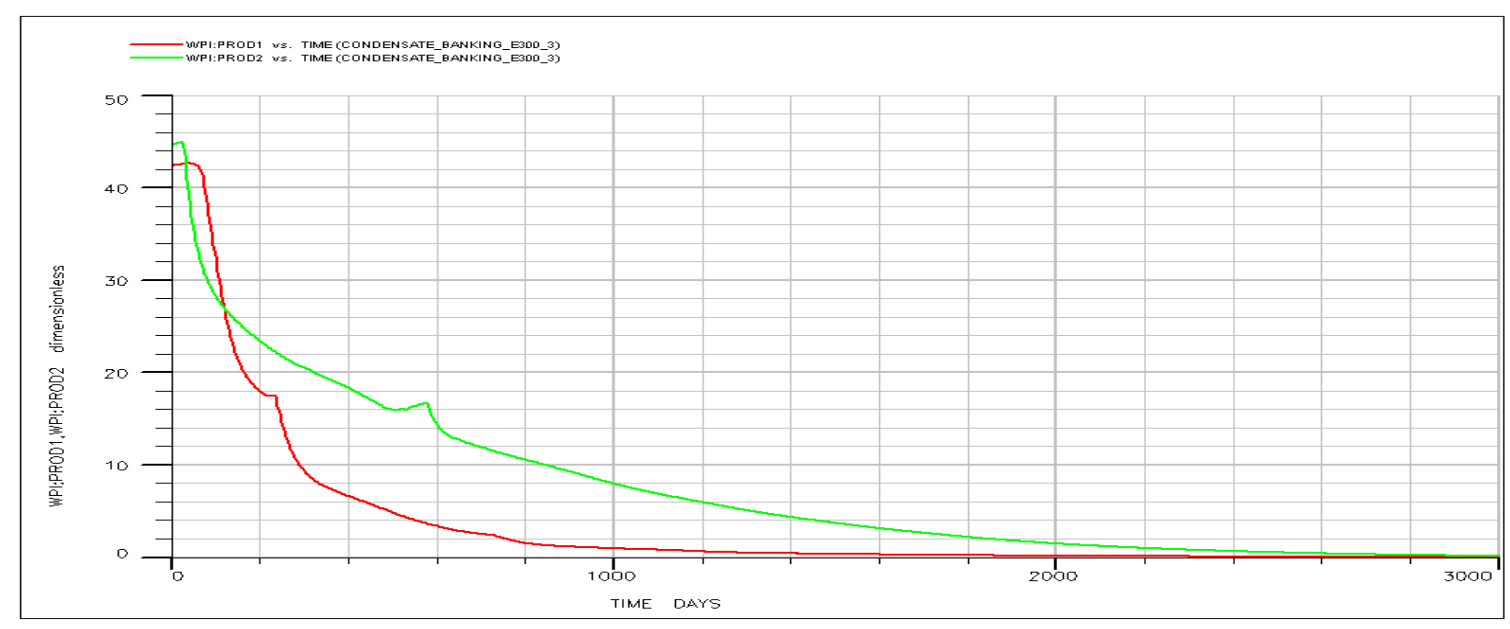

Figure 6: Well's Productivity Index

\subsection{Analysis of Field Production Performance}

In this study, the field analysis was performed with respect to each producer and the phase distribution of liquid and the gas phases respectively. The result in Figure (7) shows that PROD2 have higher liquid production rate as compared to PROD1. This is as a result of the presence of condensate banks in the immediate vicinity of PROD2

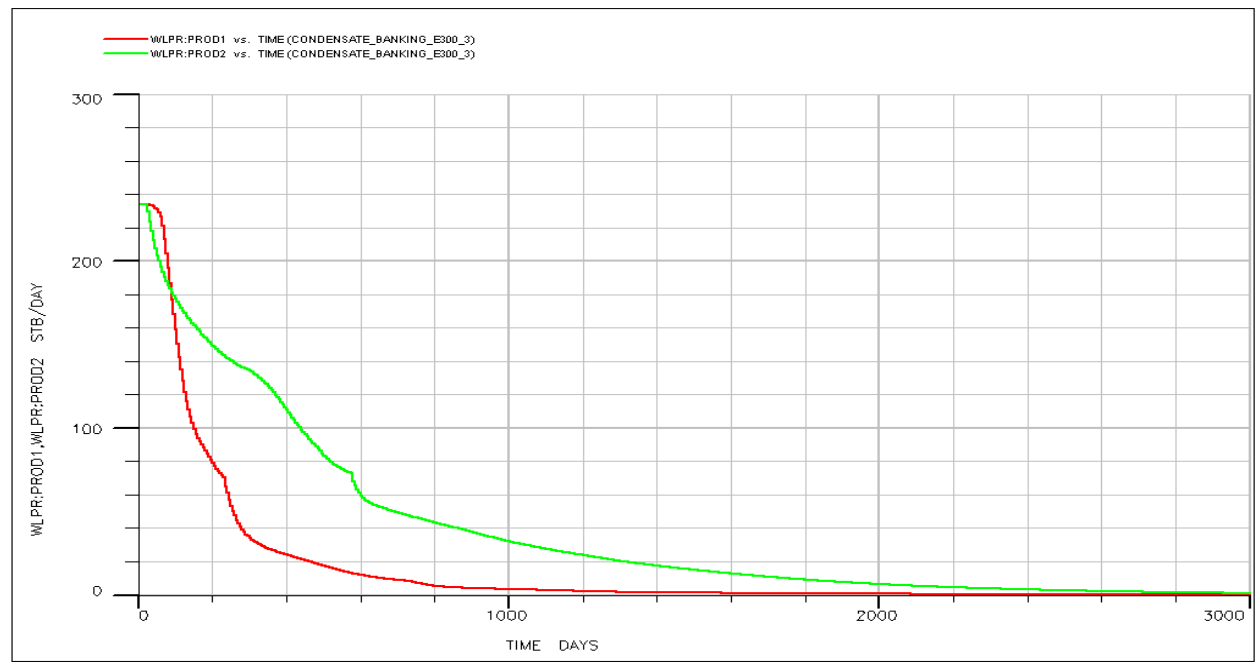

Figure 7: Well Liquid Production Rate 
Analysis of block oil (condensate) initially in place (in both gaseous and liquid phases) given in Figure (8) below shows that the amount of heavy ends hydrocarbons in liquid phase in grid bock $(20,1,5)$ is significant. This therefore explains why there is condensate accumulation in grid block $(20,1,5)$ where PROD2 is located. On the contrary, the block oil initially in place in liquid phase for grid block $(10,1,5)$ is zero. For this reason, there is no liquid (condensates) accumulation in in grid block $(10,1,5)$ where PROD1 is located. From Figure (9), the results shows that as production proceeds, the field condensate production rate, FCPR, reduces. This is as a result of gas injection project aimed at maintaining the reservoir pressure above dew point where retrograde condensation occurs. Hence, pressure maintenance via gas injection remains an optimal means of enhancing production from condensate fields.

In Figure (10), a comparative analysis of field gas initially in place in liquid and gaseous phases respectively is shown. The results shows that as production proceeds, both field gas field gas initially in place in liquid and gaseous phases declines as a result of reservoir depletion.

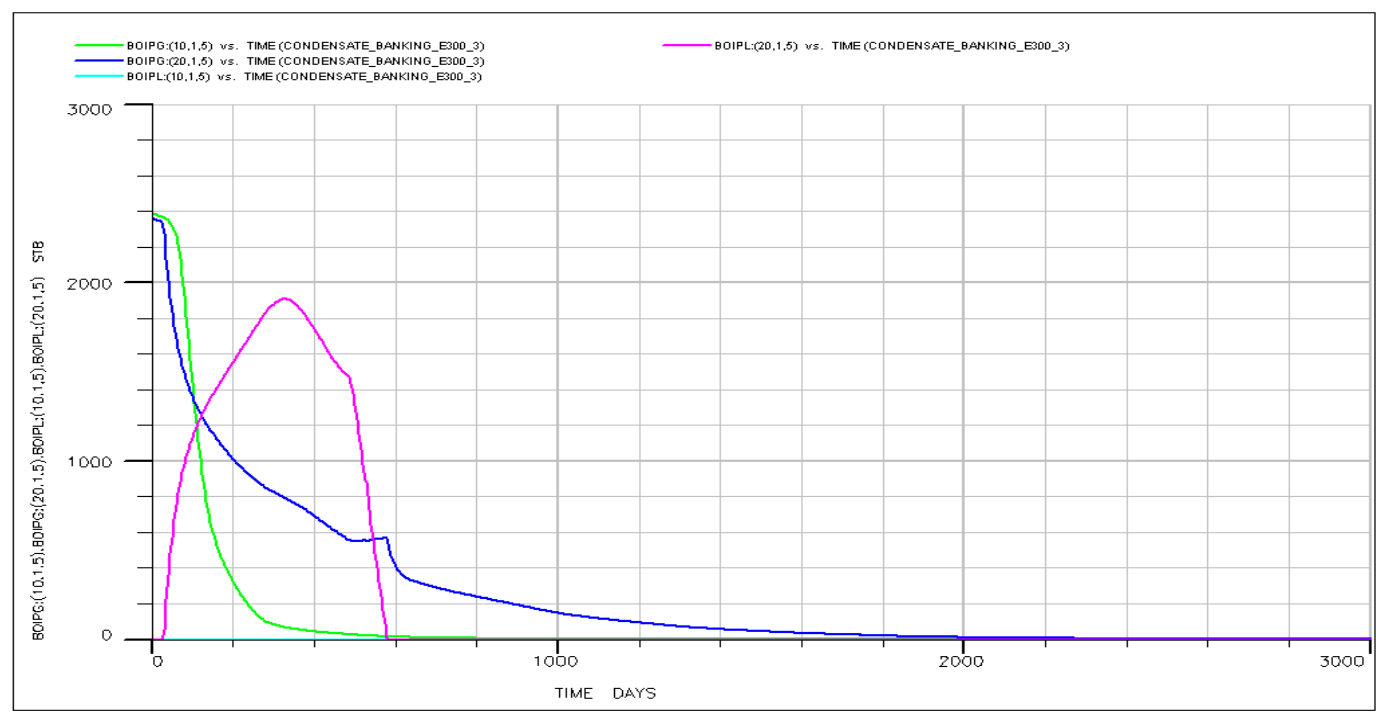

Figure 8: Condensates Distribution in Liquid and Gas Phases for Grids $(\mathbf{1 0 , 1 , 5 )}$ and $(20,1,5)$ 


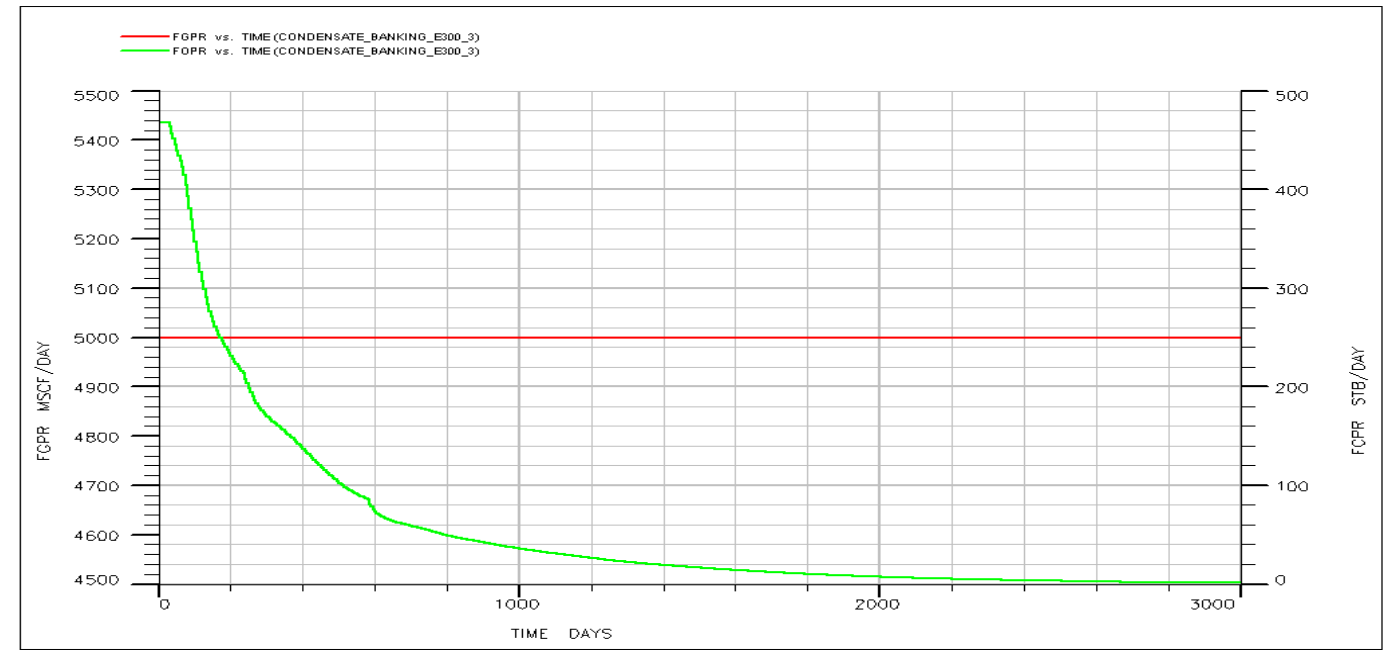

Figure 9: Field Condensate Production Rate (FCPR) versus Time
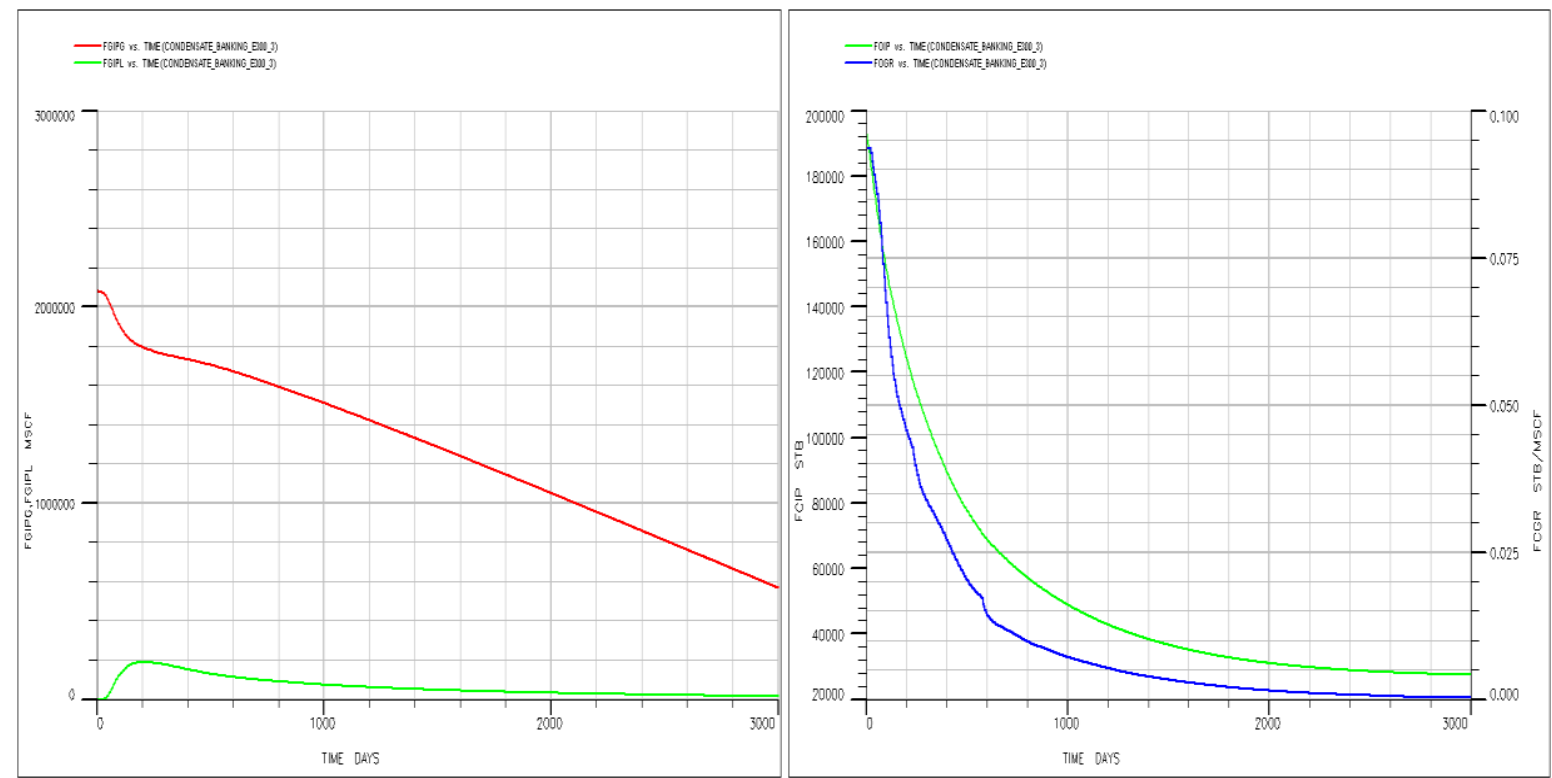

Figure 10: Field Gas Initially in Place. Figure 11: Field Condensates Initially in Place/Field in both Gaseous and Liquid Phases Condensate Gas Ratio versus Time

In the Figure (12), the heavy end hydrocarbon (C15 component) molar rates in the gaseous phase is analyzed. The result shows a retrograde behavior as characterized by the irregular decline profile. This result reflects a most topical issue regarding the development of gas condensate reservoirs where there is retrograde condensation and vaporization of the heavy ends.The field component (C15) as wet gas (FCHIP), the field component mass production rate in gaseous phase (FCGMR), the field component mass production total in gaseous phase (FCHMT) and the FCMBE is shown in Figure (13) above. The results reveals that a significant amount the $\mathrm{C} 15$ component was produced as wet gas. 


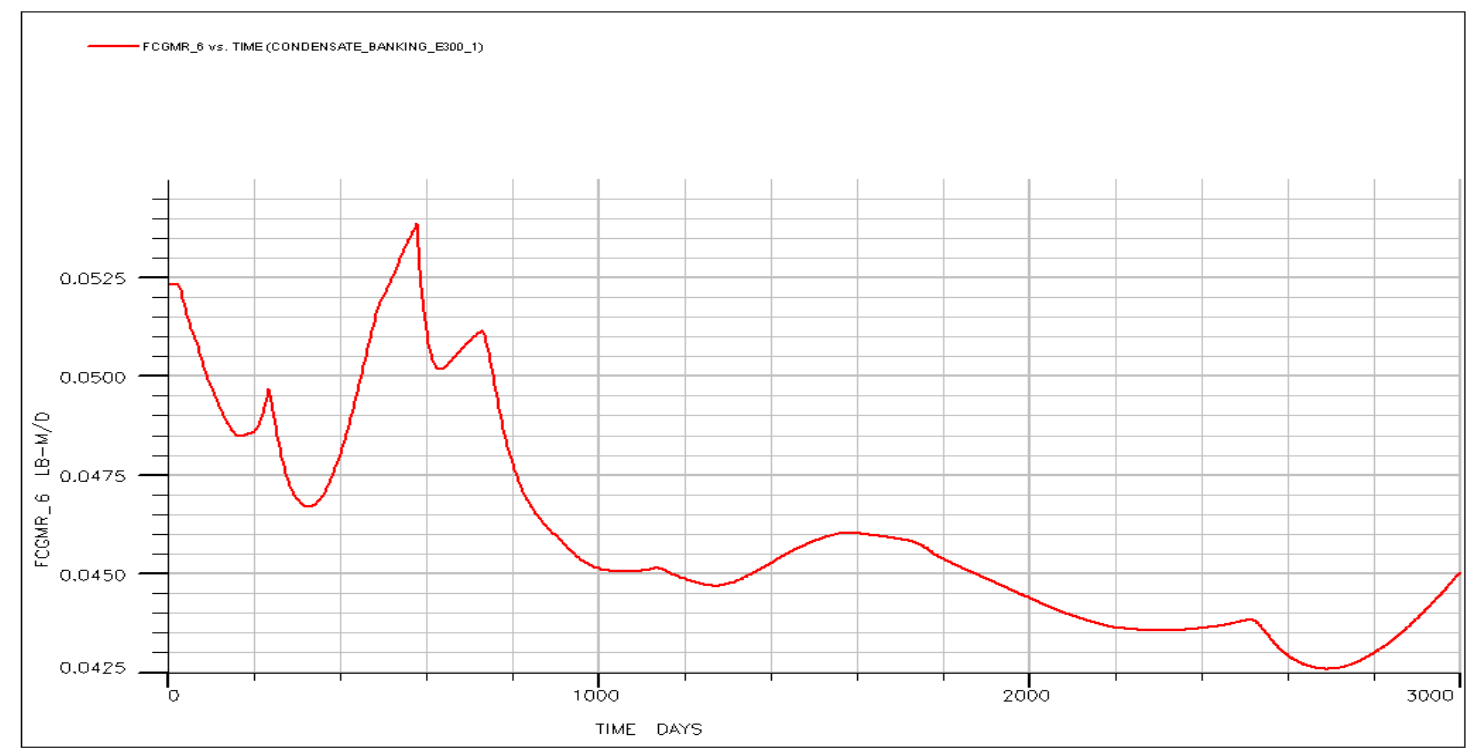

Figure 12: Field C15 Component Molar Rate in Gaseous Phase

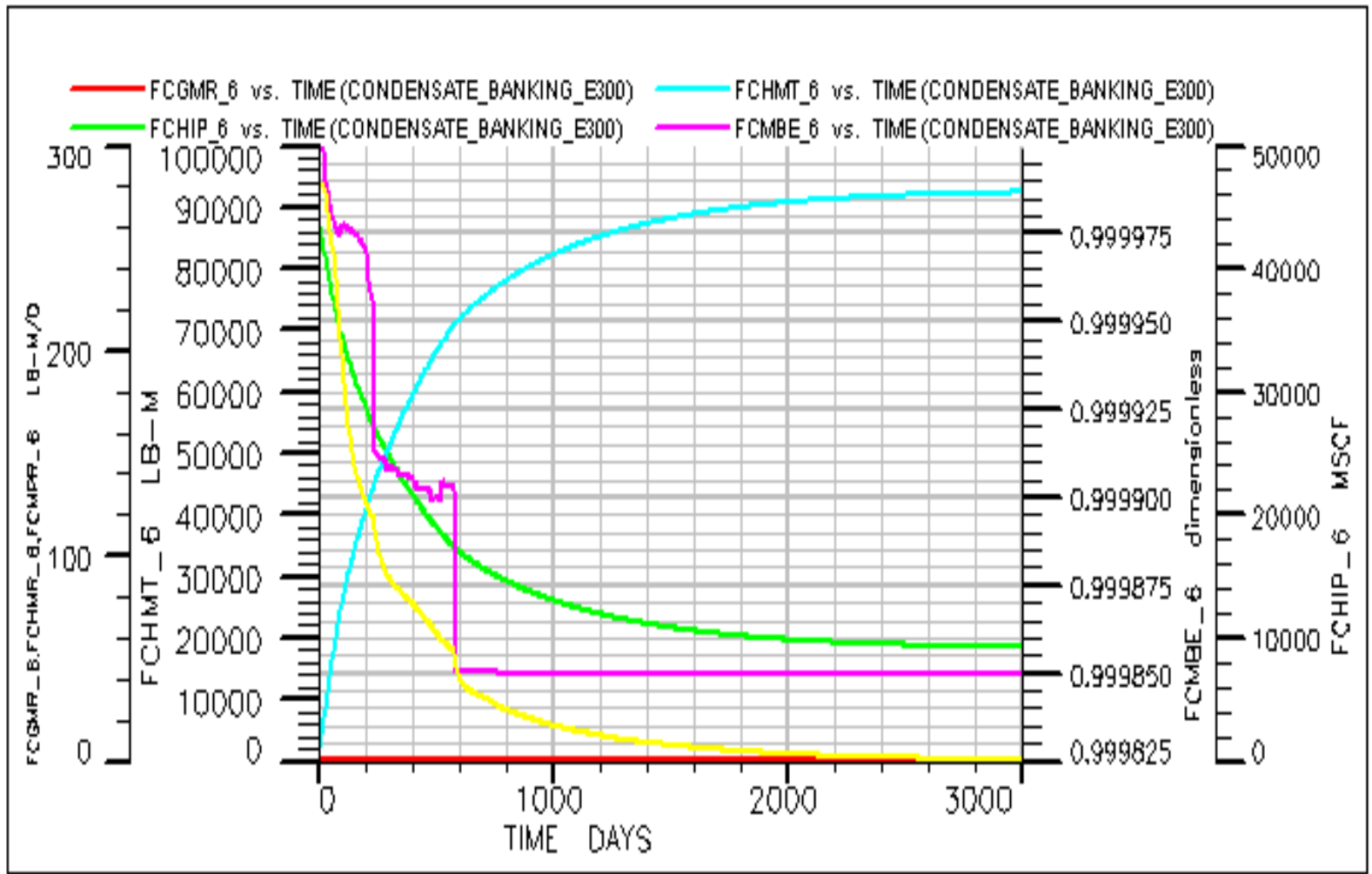

Figure 13: Heavy End [C15] Component Production History

\subsection{The Bottom-Hole Pressure History}

The flowing bottom hole pressure of INJ1, PROD1 and PROD 2 is presented below in Figure (14). The results indicate a continuous decline in the flowing bottom hole pressure of the three wells. Comparative analysis reveals that the well associated with condensate banking have a slightly faster decline. This explains why wells associated with condensates often experiences liquid load up that eventually caused large pressure drawdown in the wellbore. 


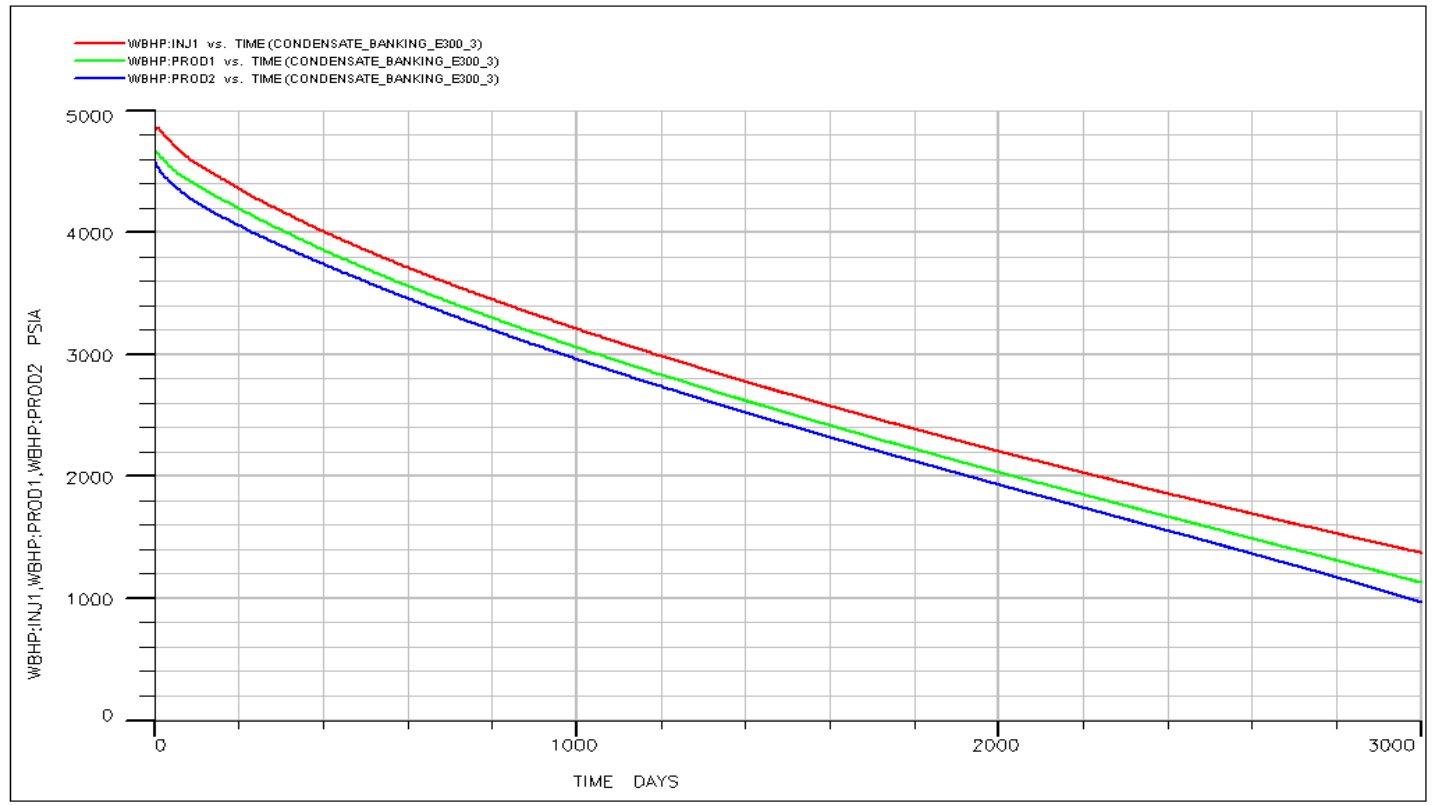

Figure 14: Well Flowing Bottom Hole Pressure

\subsection{Components Phase Distribution Analysis}

The Table (3) presents the simulated phase distribution of the components in the gaseous and liquid phases respectively. From the results of the original composition of the condensates at the start of the production, it is evidently shown that the $\mathrm{CO} 2, \mathrm{~N} 2$ and $\mathrm{C} 1$ are predominantly in gaseous phase while the heavy ends $\mathrm{C} 10$ and $\mathrm{C} 15$ were predominantly liquids. However, the $\mathrm{C} 3$ shows a near equilibrium distribution in both phases. As production proceeds up to 4 years of the reservoir life, retrograde condensation sets in and the highly soluble CO2, C3 and other volatile ends of the hydrocarbon's transits into the liquid phase. To keep the volatile ends sufficiently is gaseous phase, pressure maintenance has been proposed in this study as a viable solution. This is necessary to discourage the phenomenon of retrograde condensation in the reservoir grid blocks.

\subsection{The Influence of Reservoir Geometry on Condensate Accumulation}

Retrograde condensation is a complex phenomenon that can be affected by a variety of factors. This is because, gas condensate systems often represent an unstable non-homogenous mixture that tends to separate out with the slightest pressure change. In reservoirs with remarkable dip angle (in which gravity significantly contributes to reservoir drive energy) as used in this study, the effect of gravity segregation can often facilitate heavy ends drop out from the condensate system. The downward dip towards PROD2 can as well explain the tendency of condensate banking of the grid blocks in this vicinity. 


\section{CONCLUSION}

From this study, it has been investigated that retrograde banking caused by retrograde condensation can play an important role in the reduction of the well deliverability of a gas condensate reservoir. In summary, the following findings have been supported from our result analysis

- The presence of condensate banks causes a significant disruption in the field condensate relative saturation (due to high liquid drop out) and relative permeability to gas (resulting to mobility issues) in affected grid cells. Hence, condensate banking tendency can be easily correlated from field relative permeability/saturation history.

- Retrograde condensation reduces the relative permeability to gas and the gas saturation and can be ultimately affected by the quantum of heavy ends present in the reservoir.

- The presence of highly soluble $\mathrm{CO}_{2}$ and the freezing effect of $\mathrm{N}_{2}$ also affect the distribution of the components in the gaseous and liquid phases respectively which can be a determinant factor for condensate dropout and accumulation in the reservoir matrix.

- Moreover, reservoir geometry can facilitate gravity segregation which ultimately can lead to condensate drop out in tilted reservoirs with remarkable dip angle

\section{REFERENCES}

Abaku, G., Nwankwo, I,S \& Kinate, B,B.(2020). Effect of Flow Parameters on Liquid Loading and Tubing Lift Performance in a Gas Well. International Journal of Recent Engineering Science. ISSN: $2349-7157$

Afidick, D, Kaczorowski, N,J and Bette, S.(1994). Production Performance of Retrograde Gas Reservoir:A Case Study of the Arun Field.. Melbourne, Australia : SPE Asia Pacific Oil and Gas Conference, 1994. SPE-28749

Ahmed, T., Evans, J., Kwan, R., \& Vivian, T.(1998). Wellbore Liquid Blockage in GasCondensate Reservoirs. Society of Petroleum Engineers.doi:10.2118/51050-MS

Barnum, R. S., Brinkman, F. P., Richardson, T. W., \& Spillette, A. G.(1995). Gas Condensate Reservoir Behaviour: Productivity and Recovery Reduction Due to Condensation. Society of Petroleum Engineers.doi:10.2118/30767-MS

Chunmei, S.(2009). Flow Behaviour of Gas Condensaate Wells. A Dissertation submitted to the Department of Energy Resources Engineering, Stanford University. USA : s.n., 2009.

Du, Y., Guan, L., \& Li, D. (2004). Deliverability of Wells in the Gas Condensate Reservoir. Society of Petroleum Engineers.doi:10.2118/88796-MS

Fan, L., Harris, B,W., Jamaluddin, A., Kamath, J., Mott, R., Pope, A,G., Shandrygin, A and Whitson, H,C.(2005).Understanding Gas Condensate Reservoirs. s.l. : Oilfield

Rev.17(4),14- 27

Gringarten, A. C., Al-Lamki, A., Daungkaew, S., Mott, R., \& Whittle, T. M. (2000). Well Test Analysis in Gas-Condensate Reservoirs. Society of Petroleum Engineers.doi:10.2118/62920- 
Hinchman, S and Barree, R.(1985). Productivity Loss in Gas Condensate Reservoirs. s.l. : SPE Annual Technical Conference and Exhibition, Society of Petroleum Engineers, SPE-14203MS.

Imo-Jack, O. (2010). PVT Characterization of a Gas Condensate Reservoir and Investigation of Factors Affecting Deliverability. Society of Petroleum Engineers.doi:10.2118/140629-MS

Lal, R,R. (2003). Well Testing in Gas Condensate Reservoirs. Maters Thesis. s.l. : Stanford University.

McCain, W,D. (1990).The Properties of Petroleum Fluids. Tulsa, Oklahoma : Penn Well Publishing Company.

Silpngarmlers, N, Ayyalasomayajula, P,S and Kamath, J.(2005).Gas Condensate Deliverability: Integrated Laboratory-Simulaation-Field Study. s.l. : International Petroleum Technology Conference.

Smits, R, Van der Post, N and Al Ahaidi, S.(2001).Accurate Prediction of Well Requirements in Gas Condensate Fields.. s.l. : SPE Middle East Oil Show. Society of Petroleum Engineers. SPE68173-MS 


\section{APPENDIX}

Table 3: Components Distribution in Gaseous and Liquid Phases Respectively A: Mole Fraction Distribution in Gaseous and Liquid Phases Respectively at the Start of Production

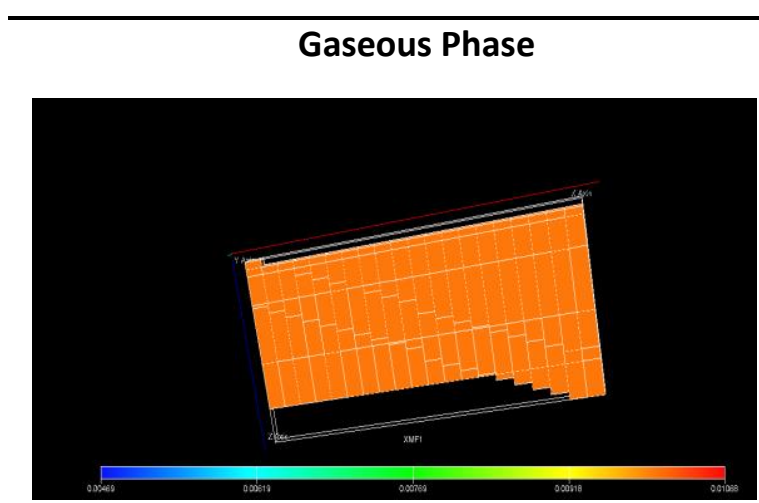

Mole Fraction of $\mathrm{CO} 2$ in Gaseous Phase

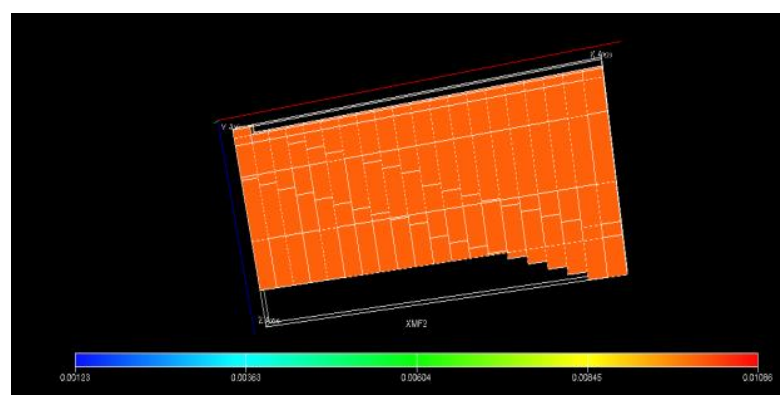

Mole Fraction of N2 in Gaseous Phase

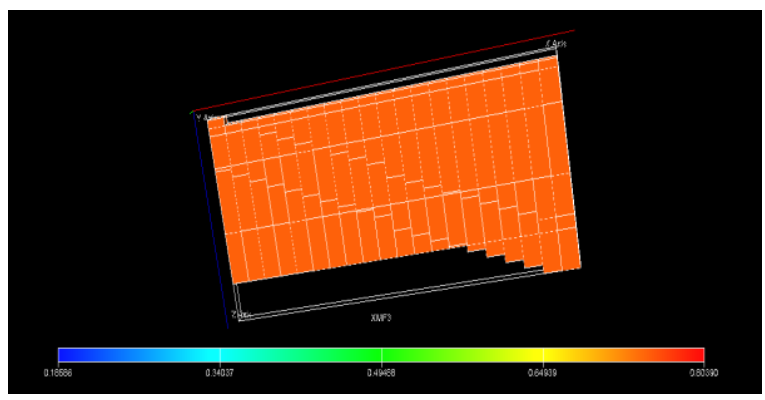

Mole Fraction of $\mathrm{C} 1$ in Gaseous Phase

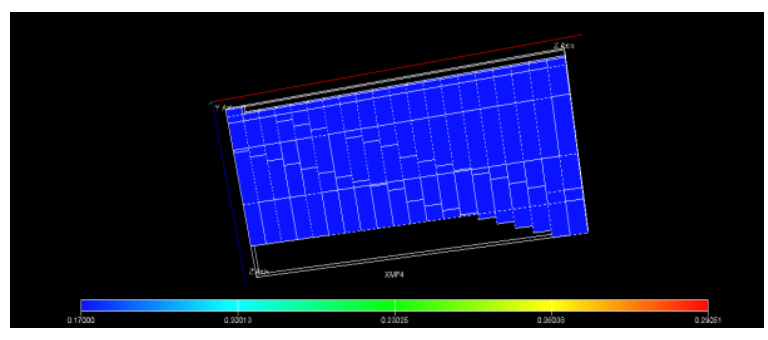

Mole Fraction of $\mathrm{C} 3$ in Gaseous Phase
Liquid Phase

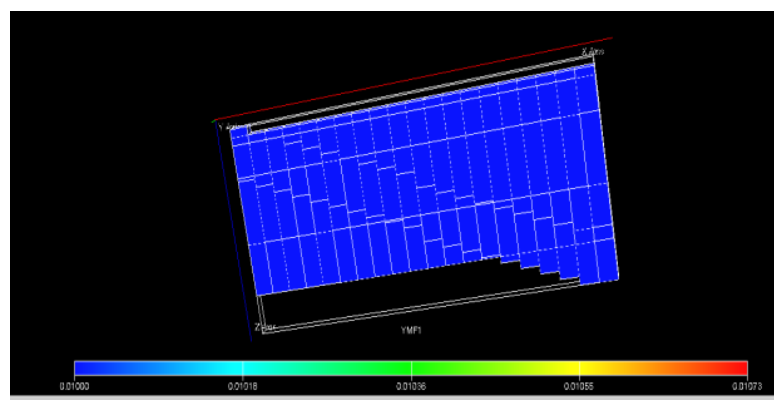

Mole Fraction of $\mathrm{CO} 2$ in Liquid Phase

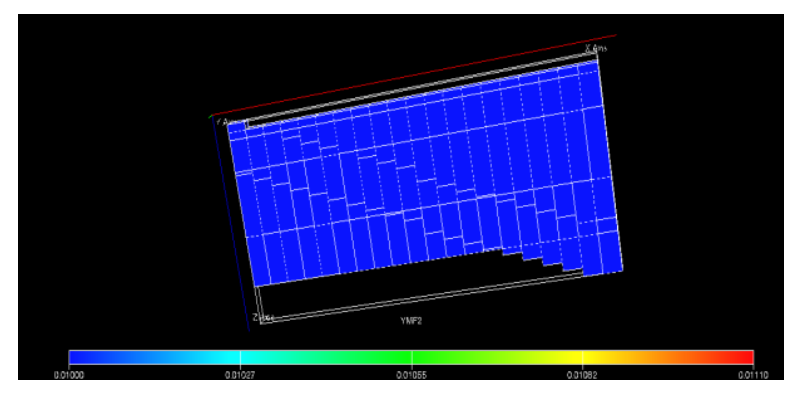

Mole Fraction of N2 in Liquid Phase

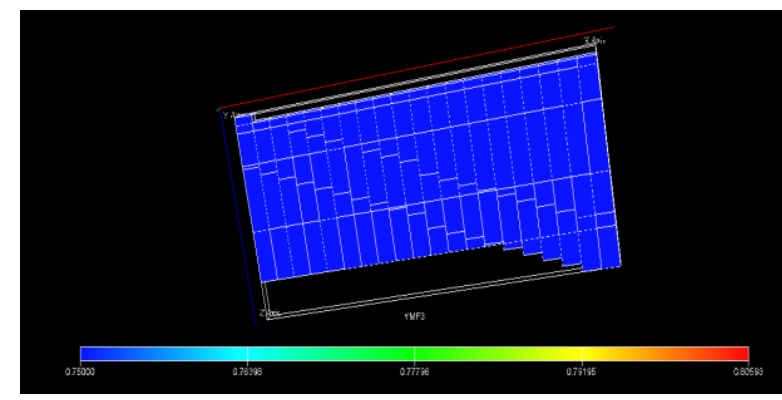

Mole Fraction of $\mathrm{C} 1$ in Liquid Phase

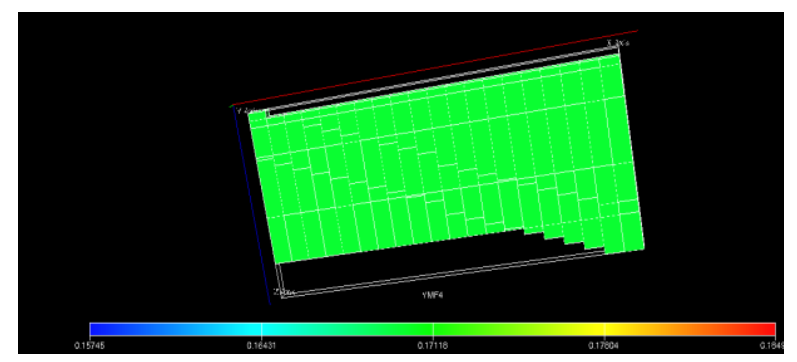

Mole Fraction of C3 in Liquid Phase 


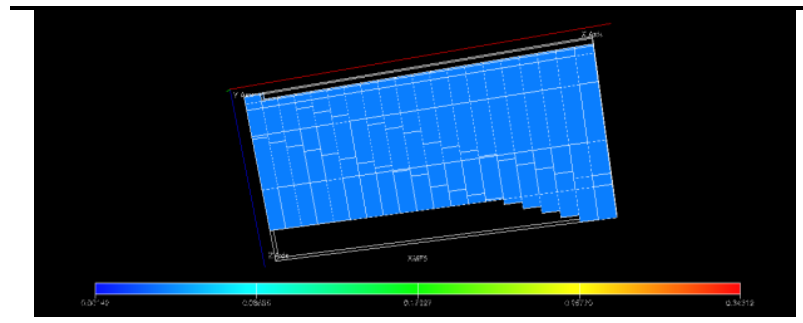

Mole Fraction of C10 in Gaseous Phase

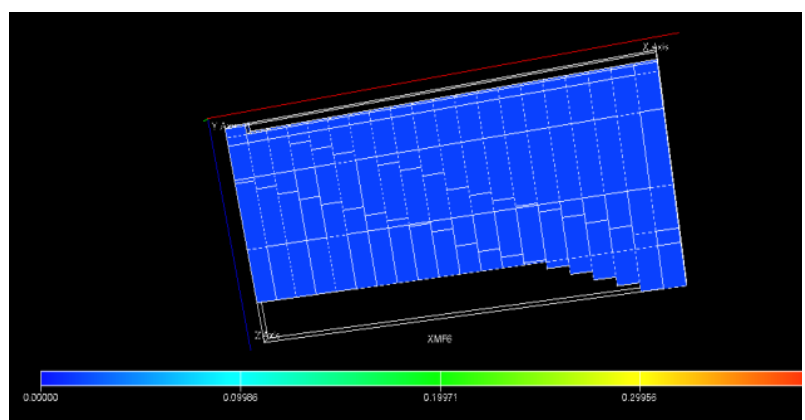

Mole Fraction of C15 in Gaseous Phase

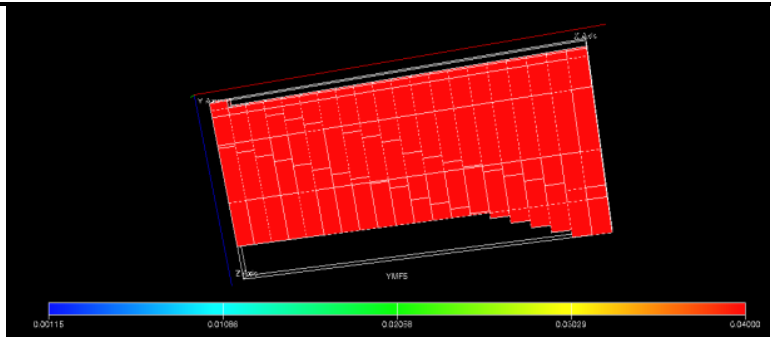

Mole Fraction of C10 in Liquid Phase

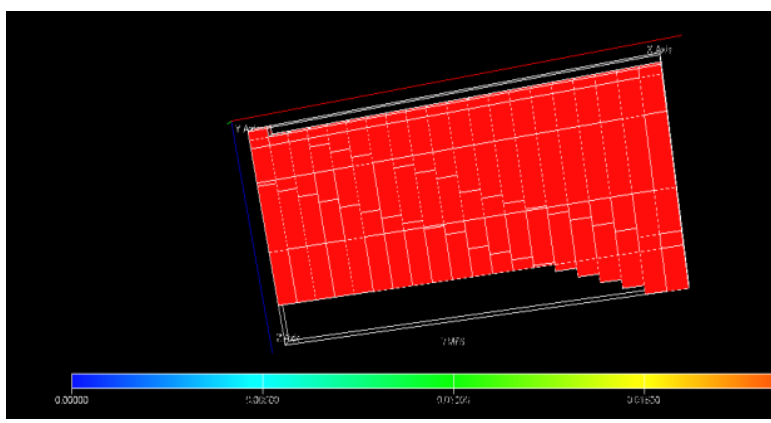

Mole Fraction of C15 in Liquid Phase

B: Mole Fraction Distribution in Gaseous and Liquid Phases Respectively After 4 years of Production

Gaseous Phase

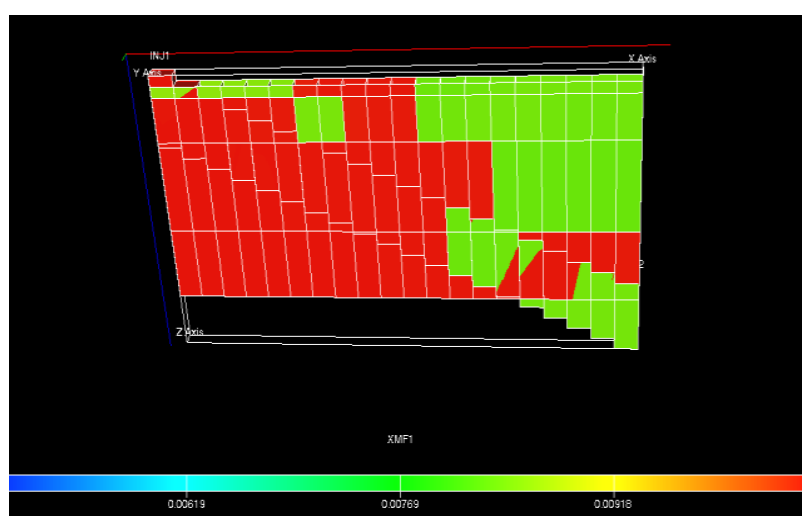

Mole Fraction of $\mathrm{CO} 2$ in Gaseous Phase
Liquid Phase

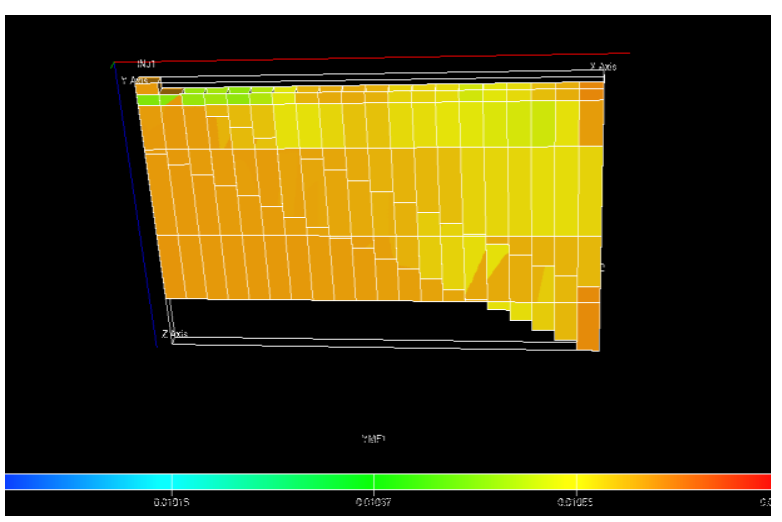

Mole Fraction of $\mathrm{CO} 2$ in Liquid Phase 

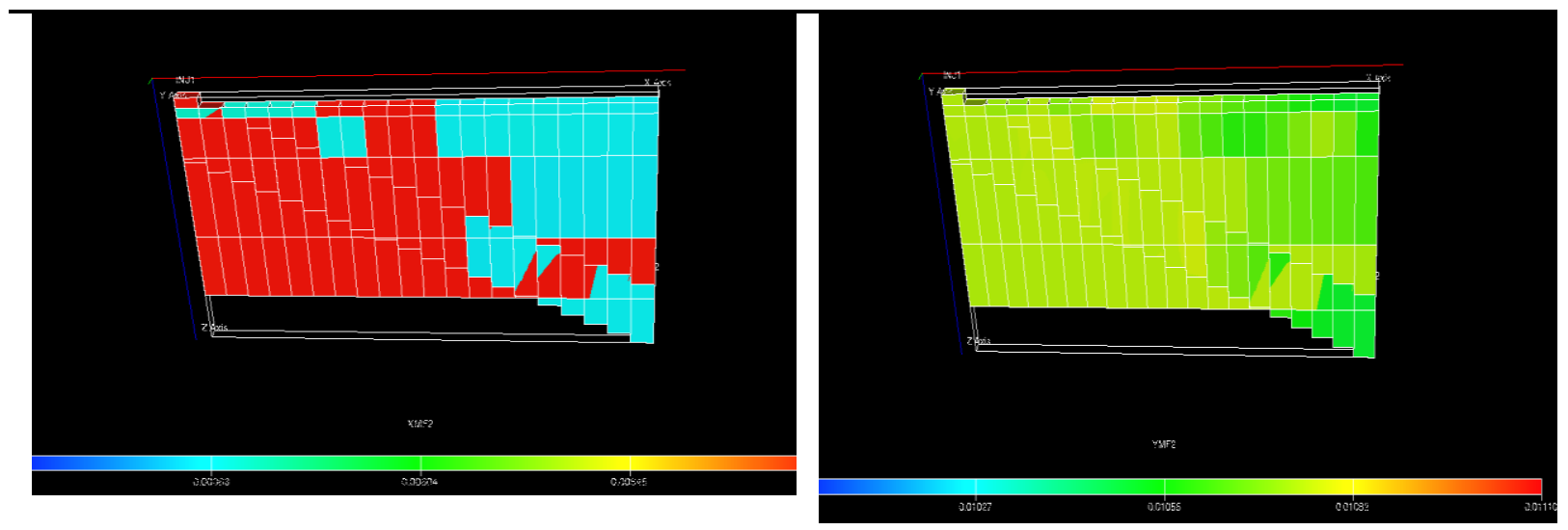

Mole Fraction of N2 in Gaseous Phase

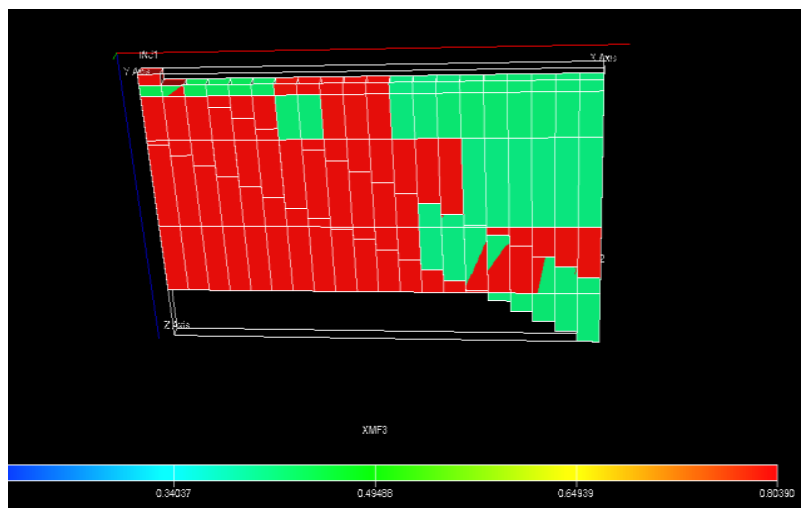

Mole Fraction of C1 in Gaseous Phase

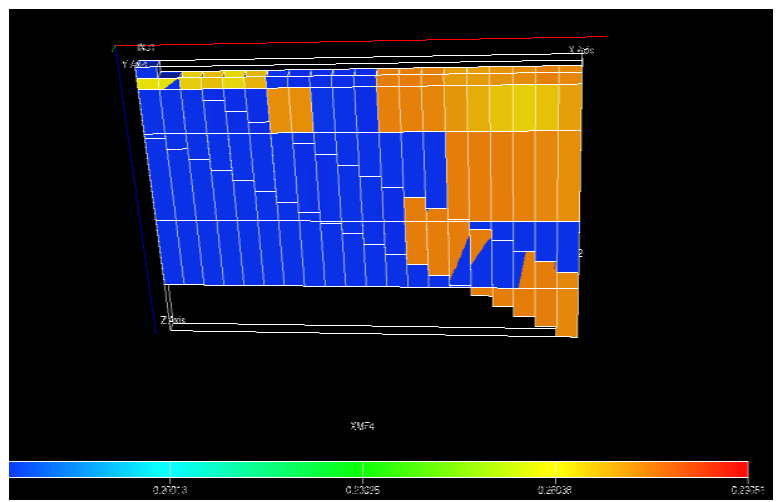

Mole Fraction of C3 in Gaseous Phase
Mole Fraction of N2 in Liquid Phase

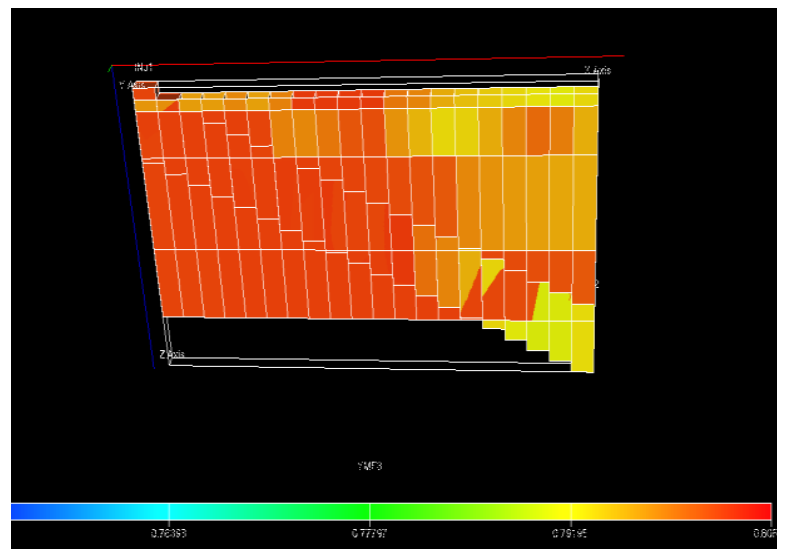

Mole Fraction of C1 in Gaseous Phase

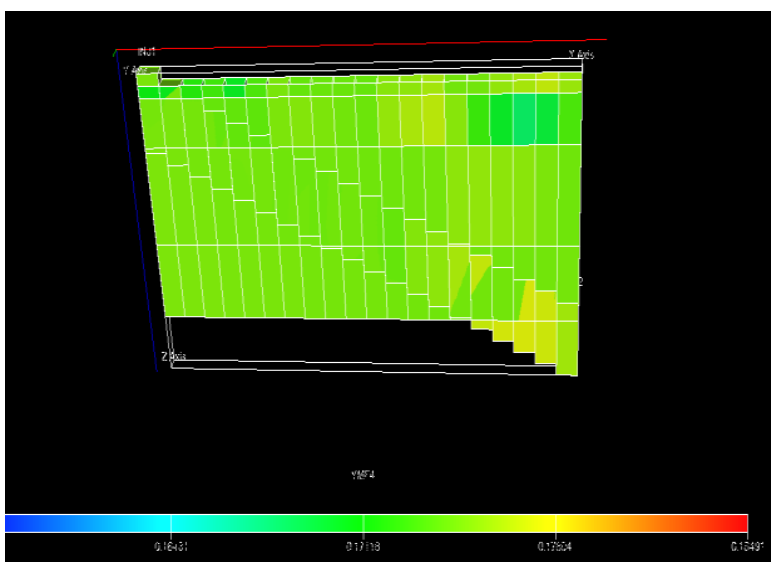

Mole Fraction of C3 in Liquid Phase 

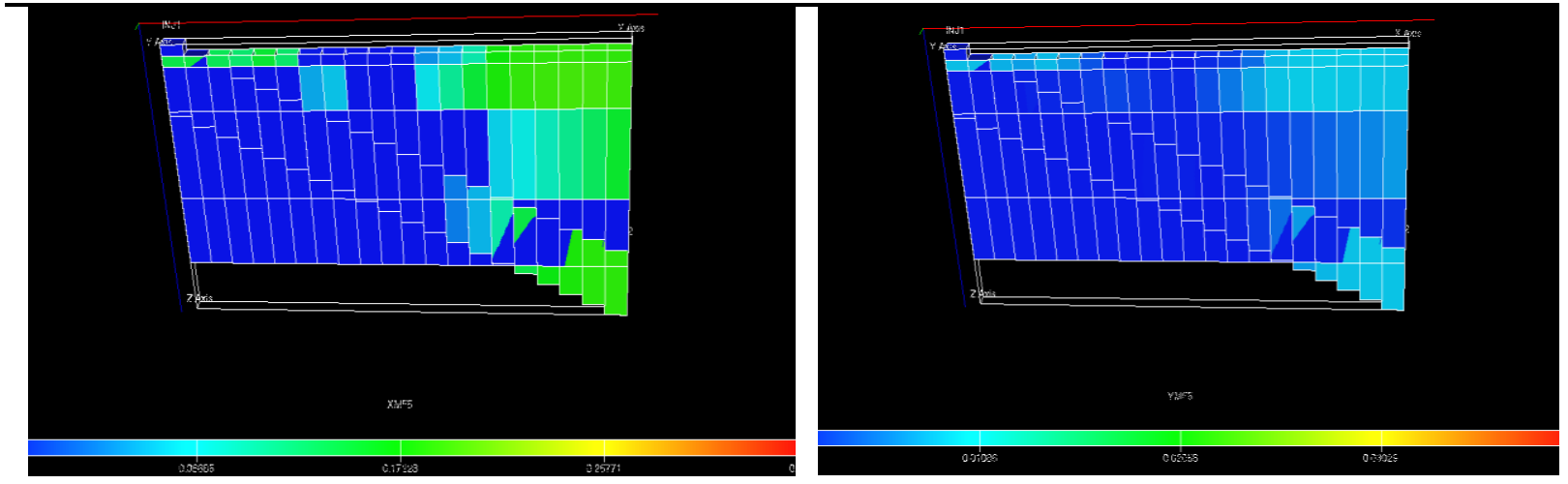

Mole Fraction of C10 in Gaseous Phase

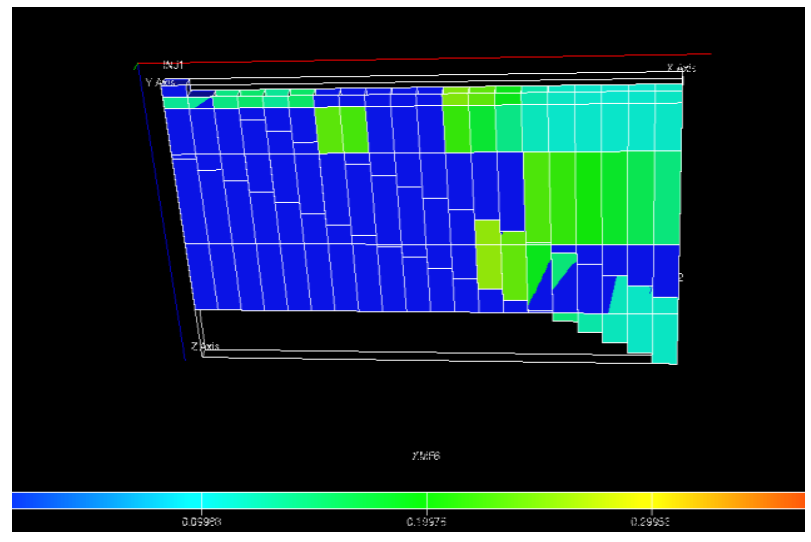

Mole Fraction of C15 in Gaseous Phase
Mole Fraction of C10 in Liquid Phase

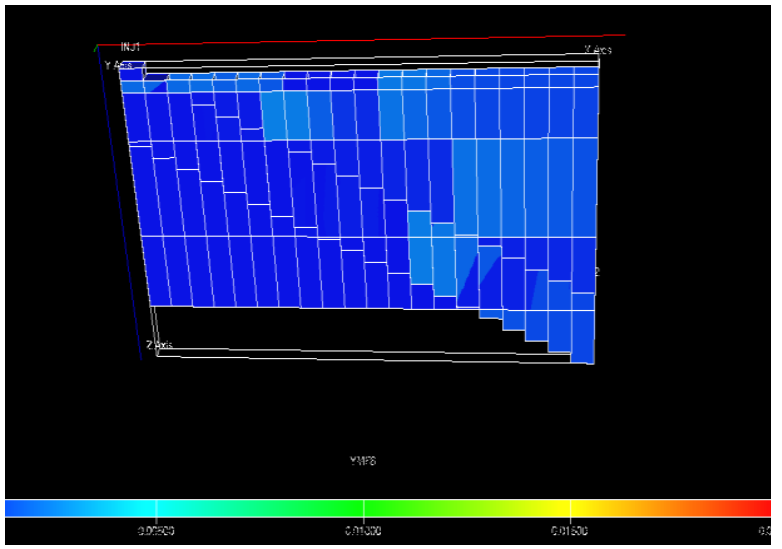

Mole Fraction of C15 in Liquid Phase 